\title{
Media Coverage of Child Abuse and Child Protection in Ethiopia
}

\section{Tseganesh Mulugeta, Bahir Dar University, Ethiopia}

\begin{abstract}
This study examines the media coverage of child abuse and child prevention whether the media promote this issue as a vital part of the public agenda. It depicts on a content analysis of news and programs of Ethiopian Television Police Program broadcasted from January 2009 to January 2012. News and programs are taken as samples for the content analysis. The data revealed that the majority of the news items and programs were not focused on children rights and abuses. It is found that the media failed to give more emphasis on the child abuse issues. The news items analyzed in this study were focus on limited themes related with child abuse and protection. This indicates that the news items or the media failed to play its part in placing the issue of child abuse and child protection on the public agenda. The media has the role of creating opportunity for broader discussion on the public agenda. Thus, it must be an instrument for the public to gain a better understanding of what child abuse means. The media should highlight children's issues so that it can pressure policy makers and the public to uphold and respect children's rights.
\end{abstract}

Keywords: Child abuse, child protection, agenda-setting, public awareness 


\section{Introduction}

Children are an important group in any society. They have only one chance of a childhood. They deserve to be protected from different kinds of abuse. Children require special care and protection because of their mental and physical immaturity. They need to be brought up in an environment capable of providing care and affection (Goel, 2009). However, they are victims of wars and civil conflict and it results on denial of basic needs, rape, loss of parents, etc.

Child abuse is one of the major social problems facing children throughout the world (MillerPerrin \& Perrin, 2007; Eileen, M., 2008). However, it varies from place to place and the culture and nature of the society (Ike \& Twumasi-Ankrah, 1999). Children in Ethiopia have rights which are ratified and adapted in the international and national level such as United Nations Convention on the Right of Children (1990), African Charter on the Rights and Welfare of the Child (1990), Constitution of the Federal Democratic Republic of Ethiopia (1995). Although they possess all rights which are recognized by international and national bodies, they are prone to different types of child abuse - physical, sexual, neglect and psychological/emotional (Genaye, 2008; Maheder, 2008; Belay, 2007; Getnet, 2001).

Many scholars believed that mass media have the power to create awareness among the societies (Kitzinger J. \& Skidmore, P., 1995; Goddard, C. \& Saunders, J.B., 2001). However, this study argued that little attention has been given to the issue of child abuse in the media. Many people's perceptions of child abuse are influenced by the knowledge and understanding they gain through the mass media. The media play a significant role in shaping and influencing public attitudes about most current issues. Researches showed that the public are informed about child abuse through media reporting (Goddard, C. \& Saunders, J.B., 2001).

Media is the major source for the public to know more about the nature of child abuse. According to Miller-Perrin and Perrin, "despite frequency of occurrence... their sensationalistic nature has made them popular subjects of the news and entertainment media" (2007, p. 233). The media has a role in raising the awareness of the public through media campaign. The style of media exposure to educate and inform the public is seen as "one of the easiest and most cost-efficient child maltreatment prevention techniques" (Miller-Perrin \& Perrin, 2007, p. 26). Through media, it's easy to create awareness among the society 
towards child abuse and child protection. The media is the instrument of change of public behavior by the way in which they address the issues of child abuse and to target the public awareness of child abuse (Pfohl, 1977, Jenkins, 1998).

In Ethiopia, however, child abuse is a complex societal issue that receives limited research and media attention. Given the power of the media to shape public perception through agenda setting, studying depictions of child abuse stories in the media is critical to explore public understanding of the issue. This study presented the results of a content analysis of child abuse and child protection coverage in Ethiopian Television Police program. Thus, the following research questions were raised: How much coverage the program gives for the issue of child abuse and child protection? and What is the role of the program in placing the issue of child abuse and child protection on the public agenda?

\section{Child Abuse and the Role of Agenda Setting}

Media play an important role in raising public awareness of children's rights. Parents, researchers, experts, government and non-government organizations and journalists, who strive for wider recognition of children's rights, must have the orientation that media has the power of safeguarding the rights and the dignity of children. The media has a crucial role to play in reporting on children's rights and in reporting abuses. In exposing and highlighting abuse, the media can also explore how exploitation of children can be stopped. The media has the task of bringing these abuses to the attention of policy makers and the public (Goddard, C. \& Saunders, J.B., 2001). According to the Convention on the Rights of the Child, the mass media have essential functions in promoting and protecting the fundamental rights of the child (1996).

Agenda setting theory can offer the field of child maltreatment critical insights into how and why audiences care about certain issues while largely ignoring others. "News organizations have the ability to control the public's agenda by choosing which topics to cover and with what frequency. Agenda setting involves the media's ability to control the topics the public perceives as important (McCombs, 2004; McLeod, Kosicki, \& McLeod, 2009). According to agenda setting theory, the frequency with which the media cover certain topics causes the audience to care more about those topics or believe they are more salient in their lives. 
Agenda-Setting theory states that the news media have a large influence on audiences that means media influenced views about important issues among the general public (Cook, et al. 1983).

\section{Methods}

For this study, the researcher used quantitative content analysis. According to Krippendorff (2004), "Content analysis is a research technique for making replicable and valid inferences from texts (other meaningful matter) to the contexts of their use." Focus group discussion was also used to gather information from the public (from Bahir Dar and Gondar towns) in order to find out whether the media play its role in creating awareness.

\section{Sources of Data}

Three years of news and programs broadcasted in Ethiopian Television Police Program from January 2009 to January 2012 were sources of data. Twenty two news segments and programs were taken as samples through systematic random sampling. In content analysis, systematic samples are favored "When texts stem from regularly appearing publications, newspapers, television series, interpersonal interaction sequences or other repetitive or continuous events" (Krippendorff, 2004, pp.115). Thus, 119 news items and 42 programs were selected for analysis. One program producer was also part of this study. The participants for the focus group discussion were selected through convenience sampling method.

\section{Unit of Analysis and Analytic Categories}

Individual news items and programs were the unit of analysis for this study. The researcher has made an effort to produce operational definitions that are as precise and unambiguous as possible. The following are the brief descriptions of the categories:

Type of story: This refers to the genre that the story belongs to. The child abuse and child protection stories were coded as - news and programs.

Theme of story: This refers to the main or central message of the stories. It was coded as predominant and subcategorized themes of child abuse and child protection coverage and presented as follows: 
Themes of the stories

\begin{tabular}{lll}
\hline Predominant themes & Sub-categorized themes \\
- & Physical child abuse & Death of children \\
- Sexual child abuse & - & Rape and attempted rape \\
- Neglect & - & Female children genital mutilation \\
- Psychological/emotional abuse and & $\bullet$ & Deficit of provision of basic needs \\
- & Children rights & Discussions/demonstrations \& trainings \\
& & \\
& - & Government \& nongovernmental actions \\
\hline
\end{tabular}

Source of story: This refers to the main source used in the stories. The sources were coded as - victimized children and/or families (direct source), police and courts, experts (social workers, psychologists, doctors etc.), government and nongovernment officials/reports.

Placement of story: This refers to the position in which the child abuse and child protection stories are presented on the program. Three categories were employed as: at the beginning, at the middle and at the end of the news segments.

The important goal in content analysis is reliability and consistency of assessment across various coders to confirm uniform in the coding as well as analysis procedures. Two trained coders conducted the coding process. An in-depth explanation was given for the coder before coding. The contents to be analyzed were chosen based on explicit and constantly applied rules. A similar set of guideline was employed throughout the research process to which both the coders had to be abided. All the 119 news items and 42 programs were analyzed for the inter-coder reliability check. The inter-coder reliability check was performed using Holsti's formula. The researcher moderated for some of the inconveniences and disagreement observed throughout the process. The problems were resolved by rigorously employing double coding mechanism. As a result, the researcher computed and come up with an overall inter-coder reliability coefficient of $.97(97.37 \%)$. Hence, this figure is more than required when compared with the standard used in most content analysis studies. "As a rule of thumb, most published content analyses typically report a minimum reliability coefficient of about 90\% or above when using Holsti's formula"(Wimmer 1983:156). 


\section{Results}

\section{Coverage of child abuse and child protection issues in the news and programs}

\begin{tabular}{lcccc}
\hline \multicolumn{3}{c}{ News } & \multicolumn{2}{c}{ Programs } \\
\hline Category & 2 & 1.68 & 0 & - \\
Physical child abuse & Prequency & Percentage (\%) & Frequency & Percentage $(\%)$ \\
Sexual child abuse & 11 & 9.25 & 0 & - \\
Neglect & 5 & 4.2 & 0 & - \\
Psycholgical/emotional abuse & 0 & - & 0 & 4.76 \\
Children rights & 6 & 5.05 & 2 & 95.24 \\
Others & 95 & 79.83 & 40 & $100 \%$ \\
Total & 119 & $100 \%$ & 42 & - \\
\hline
\end{tabular}

Out of the total news stories which were broadcasted in Ethiopian Television Police Program within the three years, only $24(20.18 \%)$ news items were dealt about child abuse issue/cases. From this figure, 2 (1.68) news items dealt about physical child abuse, 11 (9.24\%) about sexual child abuse, 5 (4.2\%) about neglect and $6(5.04 \%)$ about children rights. Psycholgical/emotional abuse was not an issue for the news stories. This data revealed that the majority of the news items $(79.83 \%)$ were focused on other crime and related issues other than children issues. Child abuse and child protection issues are not the main topics in the news of the police program. These issues are not in the news agenda. This, in turn, indicated that the news items did not play its part in placing the issue of child abuse and child protection on the public agenda.

Similarly, out of the total programs which were broadcasted in Ethiopian Television Police Program, only $2(4.76 \%)$ programs were dealt about children. The other programs accounted $40(95.24 \%)$. This shows that the majority of the program (95.24\%) were focused on other crime issues which are not related with children. According to agenda-setting theory, by choosing the topics to cover with what frequency, the media set the agenda for the public. Child abuse and child protection issues were not the main topics in the program as well. The theme of the two stories was about child trafficking. From the two stories, the first used direct sources and the other quoted police and court reports. 


\section{Themes and placement of the stories in the news}

\begin{tabular}{|c|c|c|c|c|c|}
\hline & & \multicolumn{2}{|c|}{ Placement of stories } & \multicolumn{2}{|c|}{ Themes } \\
\hline \multirow[t]{2}{*}{ Category } & & Frequency & Percentage & Frequenc & Percentage \\
\hline & & & $(\%)$ & y & $(\%)$ \\
\hline Death of children & At the end & 2 & 8.33 & 2 & 8.33 \\
\hline \multirow[t]{2}{*}{ Rape and attempted rape } & At the middle & 2 & 8.33 & 10 & 41.67 \\
\hline & At the end & 8 & 33.33 & & \\
\hline $\begin{array}{l}\text { Female Children genital } \\
\text { mutilation }\end{array}$ & At the end & 1 & 4.17 & 1 & 4.17 \\
\hline \multirow[t]{2}{*}{ Deficit of provision of basic needs } & At the middle & 1 & 4.17 & 5 & 20.83 \\
\hline & At the end & 4 & 16.67 & & \\
\hline $\begin{array}{l}\text { Discussions and trainings about } \\
\text { children rights }\end{array}$ & At the end & 4 & 16.67 & 4 & 16.67 \\
\hline $\begin{array}{l}\text { Government \& nongovernment } \\
\text { actions }\end{array}$ & At the end & 2 & 8.33 & 2 & 8.33 \\
\hline Total & & 24 & $100 \%$ & 24 & $100 \%$ \\
\hline
\end{tabular}

While the program reported the death of children, they placed it at the end of the whole news items. Two of the stories $(8.33 \%)$ which dealt about the rape and attempted rape were broadcasted at the middle and eight $(33.33 \%)$ at the end. The story about female children genital mutilation $(4.17 \%)$ was given place at the end of the news items. One $(4.17 \%)$ and four (16.67\%) stories which dealt about child neglect (failure to provide adequate food and leaving dangerous equipments carelessly) were given place at the middle and at the end of the news items respectively. 4 (16.67\%) news items dealing with discussions and trainings about children rights and $2(8.33 \%)$ stories which dealt about government and nongovernment actions were presented at the end of the stories.

Where the news stories were apeared in the news segment give an idea about the importance of the issue. Various media researchers believe that the location of stories is one of the factors contributing to decide the prominence of certain issues on the public agenda. Maxwell McCombs M. and Shaw D. established "position and length of a story as the two main criteria of prominence" (Griffin 2006). In this regard, a news story at the beginning of the news segement is a representation of prominence and significance. Stories presented at the 
beginning have an impact in capturing the viewers' attention and may suggest stress rather than news items at the middle or at the end. Television news offers numerous cues about salience - the opening story on the newscast, length of time devoted to the story, etc. These cues repeated day after day effectively communicate the importance of each topic (McCombs M. pp.1). In order to determine the level of importance attached to the news items, the items were classified into three (at the beginning, at the middle and at the end) based on the position where the news appeared and the airtime they were given in the program. But, it is found that none of the news items which dealt about child abuse and child protection were presented at the beginning of the newscast. Even, the majority of the news items were presented at the end. This shows that the role the media play in placing the issue is under question mark.

Regarding the themes of the news stories, 2 (8.33\%) news dealt about the death of children, which were committed by one of their family members. 10 (41.67\%) news items were mainly focused on rape and attempted rape. News items which dealt about leaving dangerous equipments carelseely (Neglect) were 5 (20.83\%). Female children genital mutilation accounts $1(4.17 \%)$. Discussion/demonstration and training about children rights and government \& nongovernment actions accounted the rest 4 (16.67\%) and $2(8.33 \%)$ respectively. Children need protection and safeguards. Policy makers and other concerned bodies set a rule which gives protection for children against violence and have been working to ensure children protection. Especially, the media, since they address vast audience, should play a major role with other stakeholders. Kitzinger (2004) stated that the media can play an important role in exposing the issues and perceptions of child abuse, either confronting or evading certain aspects of the abuse. It is found that the news items analyzed in this study focused on limited themes. Based on the data, the issue of rape and attempted rape holding 41.67\% were dominant themes. According to the producer of the program, they gave coverage for any child abuse and right issues when they receive report from different central and regional police quarters and when government or non-government organizations (NGOs) conducted meetings, workshops and trainings. This fact shows that the program didn't have their own schedules for covering the issues and they were event oriented. Most of the news items which dealt about child abuse and child protection were based on the court trial. 


\section{Sources used in the news stories}

\begin{tabular}{lcc}
\hline Category & Prequency & 8.33 \\
\hline Victimized children and/or families & 2 & 70.83 \\
Police reports and court trials & 17 & 8.33 \\
Experts (social Workers, Psychologists, Doctors) & 2 & 12.5 \\
Government and nongovernment officials/reports & 3 & $100 \%$ \\
Total & 24 & \\
\hline
\end{tabular}

From the total 24 news items analyzed, $2(8.33 \%)$ were quoted victimized children and/or families as direct sources, $17(70.83 \%)$ quoted police reports and court trials, $2(8.33 \%)$ quoted experts and $3(12.5 \%)$ were government and nongovernment officials/reports. As the program is focused on crime and related issues, police and courts were most frequently quoted sources. This is also true with what the producer replied. The most common sources for their news are courts and police. In almost all cases, the police stations and officers approach them with a report. For insuring children right, families, communities, experts like social workers and psycholgists have great responsibilities. But it seems the media didn't give due attention. They were quoted in relatively less number that is $8.33 \%$.

The credibilty of news depends in some way on the various sources that were used in the news. On this aspect, the program had limitations. This study found that only 3 (12.5\%) news items quoted government and nongovernment officials/reports. From this least quoted instance, however, the main issue was promoting their works. According to the Convention on the Rights of the Child, the mass media have essential functions in promoting and protecting the fundamental rights of children. The research found that the media did not play an important role in raising public awareness of children's rights.

\section{Major Findings from the Focus Group Discussion}

Most of the participants did not have a clear understanding of what sexual child abuse means except rape. Their understanding depends upon the stories they heard on the media and they observed in their localities. However, the term child sexual abuse is a multi-faced phenomenon not only including rape but other incidents such as fondling, child pornography, 
when the child is used for the sexual stimulation of another person (Miller-Perrin \& Perrin, 1999). For many parents, corporal punishments are the appropriate behavior of disciplining children: beating unnecessarily with a piece of stick, spanking them with leather strap, slapping, burning or scalding and paddling are common. And as a discipline, children undertake duties inappropriate to their physical ability. The culture where they live in affects the way parents raised their children. This data is supported by Belay Hagos (2006) which revealed that parents usually show their power through different mechanism such as food deprivation. But, the parents in this study claimed that it's 'for the child's own good.' They believed it as normal ways of disciplining children.

Even if the parents used food deprivation as discipline strategy, most of them did not have the awareness about child neglect and psychological abuses even on its existence. For them, humiliating or insulting children in front of other people; shouting, yelling or screaming; swearing or cursing the child; lack of attention and love were not part of abuse. Some of the parents also failed to provide basic needs. They consciously deprived food to discipline their children. They also failed to provide proper supervision and abandon the children at a difficult situation or dangerous places in and around the house. This showed that most of the children are suffered from neglect. Researches show that one of the factors for children in Ethiopia to be vulnerable to risks of abuse is poverty (Belay, H. 2008; Belay, H. 2001). Most of the community is very poor. There is no-one to care for the children while parents went to work and this is one of the reasons for the children to prone to neglect and abuse.

Among the parents, there were arguments about children rights. For some, children right is not important when they compared it with other social problems they have in hand. There are priorities other than their children rights. The time parents spend in their day to day activities also affects the behavior of the parents not to respect and protect their children's rights.

A father from Bahir Dar town admitted that,

I have seven family members and I'm the only one who has got a job. My attention is always on how I can allocate my salary to food, house rent and to other basic needs. I don't have the time or the courage to know what the rights of my children are. For me, it's waste of time. 
Some of the parents argued that there was no way for them to know the specific rights of children in detail. Here, the role of media is important. Since parents did not have the awareness on the rights of children, those concerned bodies need to make greater efforts to use the media constructively. Media is the key to improve parent's understanding of child abuse, to clarify its causes and consequences and to draw attention to ways of preventing children from abuse. Some parents, on the other hand, did not believe on the right of children at all. In Ethiopia, there are proverbs that discourage the rights of children. However, some of the participants have not only the knowledge of children rights but also how to practice these rights. They wanted their children to grow in a safe environment and to possess all their rights. For them, the children are part of the family so they let their children to express their views in any matters affecting the family.

\section{The program as an intervention strategy}

The data from the focus group discussions revealed that the program did not focus on child abuse and child protection issues. The parents believed that broadcasting the news related with child abuse have significance for others to learn from that experience and should be broadcasted every time in order to gain more insights on how to protect children from abuse. It should be served as a caution for the rest of the society. That is the role of the media. Studies also support the idea that the media has the power to create awareness among the society by providing more contexts in the stories such as the causes, consequences, ways of prevention and interventions and persuade policy makers. As Miller-Perrin and Perrin (2007), media is one of the child abuse prevention strategies. Intervention is needed to overcome the problem. Thus, the media is one of the intervention strategies to prevent and teach the society about the fatalities of the issue.

\section{Conclusion and Recommendations}

Children are human beings who need special attention and protection from the society. The society has the role to save children from the fatalities of abuse and it is, therefore, a pity to ignore when they are being abused or neglected. In this regard, the media is valuable instrument of attitude and behavior of individuals in upbringing and prioritizing children's rights and dignity. 
The finding of this study revealed child abuse and child protection issues are not the main topics in the news of the police program. These issues are not in the news agenda. Similarly, the majority of the programs were focused on other crime issues which are not related with children. Child abuse and child protection issues were not the main topics in the program as well.

The majority of the news items which dealt about child abuse and child protection were presented at the end. This shows that the role the media play in placing the issue is under question mark. The dominant theme of the news items were rape and attempted rape followed by crimes caused by neglect. Court trials and police reports were the common sources for the news. Less attention has been given to use families, communities, experts like social workers and psycholgists as sources.

Thus, media should highlight children's issues so that it can pressure policy makers and the public to uphold and respect children's rights. In addition, it must be an instrument for the public to gain a better understanding of what child abuse means, its causes and consequences. The attention must be directed toward the identification and elimination of all kinds of child abuse. Media professionals with other stakeholders must ensure and highlight the rights of children in their reporting. Researchers and professionals who work on the wellbeing of children become effective if they use the media as the major persuasive technique to child protection policies. The media has the power to affect the knowledge of people and the child protection policies and practices. If Ethiopian Television police program play its role in creating awareness about the issue, parents will begin to pay more attention to it than ever before. It has the power to influence the public knowledge/understanding of child abuse through its coverage. Thus, the children will be protected from abuse. 


\section{References}

Belay, H. (2001). Local Perceptions of Children's Needs and Rights in North Wollo, Ethiopia, Publications Catalogue of Save the Children Denmark, Addis Ababa.

Belay, H. (2007). Abuse \& Neglect: Experiences of Orphan \& Vulnerable Children in Addis Ababa. Proceedings of the 6th National Conference of the Ethiopian Psychologists Association, Addis Ababa.

Belay, H. (2008). Sexual Abuse and Exploitation of Boy Children in Addis Ababa. Bright for Children Voluntary Association (BCVA). A study supported by Save the Children Denmark, Addis Ababa.

Child Sexual Abuse in Sub-Saharan Africa: A Review of the Literature. (2011). East, Central and Southern African Health Community

Cook L.F., Tyler R. T., Goetz G. E., Gordon T. M., Protess D., Leff R. D., et al. (1983) Media and Agenda Setting: Effects on the Public, Interest Group Leaders, Policy Makers, and Policy. Public Opinion Quarterly, 47(1), 16-35.

Eileen, M. (2008). Effective Child Protection. $2^{\text {nd }}$ ed. Sage Publications Ltd.

Genaye, E. (2008): Effectiveness of “Children's Right Pictorial Booklet” in Awareness Creation of Children on Child Rights, (Unpublished MA Thesis), Addis Ababa University, Addis Ababa.

Getnet, T. (2001). Obstacles, controversies and prospects surrounding child abuse management in Addis Ababa. Northeast African Studies, Vol 8 (1), 115-141.

Goddard, C. \& Saunders, J.B. (2001). Child Abuse and the Media. Issue no. 14. National Child Protection Clearinghouse, Australia.

Goel, V. (2009). Children's human rights in underdeveloped country: A study in Ethiopian perspective. African Journal of Political Science and International Relations, Vol. 3 (4), pp. 142-155.

Griffin, E. (2000). A first look at communication theory (4th ed.). Boston: McGraw-Hill.

Griffin, E. A. (2006). Communication: A First Look AT Communication Theory, 6th ed. McGraw-hill.

Guidelines for Journalists and media professionals, (2002). Child Rights and the Media: Putting Children in the Right. International Federation of Journalists. 
Ike A. Chris \& Twumasi-Ankrah K. (1999), Child Abuse and Child Labour Across Culture: Implications for Research, Prevention and Policy Implementation, Journal of Social Development in Africa, 14, 2,109-118

Ike A. Chris \& Twumasi-Ankrah K. (1999). Child Abuse and Child Labour Across Culture: Implications for Research, Prevention and Policy Implementation. Journal of Social Development in Africa, 14, 2,109-118

Jenkins, P. (1998). Moral Panic: Changing Concepts off the Child Molester in Modern America. Yale University Press, New Haven.

Kitzinger, J. \& Skidmore, P. (1995). Playing safe: Media coverage of child sexual abuse prevention strategies. Child abuse Rev. 4:47-56.

Krippendorff K. (2004). Content Analysis: An Introduction to Its Methodology. $2^{\text {nd }} \mathrm{ed}$. Sage Publications, USA.

Maheder B. (2008). Child Abuse and Neglect and Alternative Policy Solutions. Dr Deborah Zinn, Dr Richard Kordesh, Dr Alice Butterfield Johnson, Ato Zena Berhanu (Eds.), Ethiopian Social Policy Reader, Vol. 1. Addis Ababa University.

McCombs M. (2004). Setting the Agenda: The mass media and public opinion. Malden, MA, Blackwell Publishing Inc.

McLeod, J.M., Kosicki, G.M., \& McLeod, D.M. (2009). Levels of analysis and communication science. Thousand Oaks, CA: Sage.

Miller-Perrin C.L. \& Perrin, R.D. (1999). Child Maltreatment: An Introduction. Sage Publications, Inc.

Miller-Perrin C.L. \& Perrin, R.D. (2007). Child maltreatment: An introduction, 2nd ed. Thousand Oaks, CA: Sage.

Pfohl, S. (1977). The 'Discovery' of Child Abuse. Social Problems, vol.24(9), 310-323.

Wimmer, R. (1983). Mass Media Research: An Introduction. California. Wadsworth Publishing Company.

Yemataw Wondie, Workie Zemene, Biruk Tafesse, Konrad Reschke \& Harry Schröder. (2011). The Psychosocial Consequences of Child Sexual Abuse in Ethiopia: A CaseControl Comparative Analysis. Journal of Interpersonal Violence, vol. 26 no. 10 